\title{
MARGARETH RAGO E "AS MARCAS DA PANTERA”: POR UMA HISTÓRIA FILÓGINA E LIBERTÁRIA
}

\author{
MARGARETH RAGO AND "THE MARKS OF \\ THE PANTHER”: FOR A PHILOGINAL AND \\ LIBERTARIAN HISTORY
}

Paloma Czaplal

\begin{abstract}
RESUMO
Resenha do livro As marcas da pantera: percursos de uma historiadora, de Margareth Rago.

Palavras-chave: Margareth Rago; As marcas da pantera; história filógina e libertária
\end{abstract}

\begin{abstract}
Review of the work As marcas da pantera: percursos de uma historiadora, by Margareth Rago.

Keywords: Margareth Rago; The marks of the panther; philoginal and libertarian history
\end{abstract}

RAGO, Margareth. As marcas da pantera: percursos de uma historiadora. São Paulo: Intermeios, 2021. 560 p. 
Aqueles e aquelas que se encontram no campo da história das mulheres e da filosofia da diferença, há muito esperavam por um livro que concentrasse a produção intelectual de Margareth Rago, uma das historiadoras feministas brasileiras mais expressivas na contemporaneidade. Finalmente sua imensa obra foi compilada no livro As Marcas da Pantera: percursos de uma historiadora (2021), uma coletânea de artigos publicados pela autora entre os anos de 1993 e 2020, que tratam sobre diferentes temáticas: teoria da história, gênero, feminismos, anarquismo, sexualidade, subjetividade, arte feminista, neoliberalismo, dentre outras.

Graduada em História pela Universidade de São Paulo, onde também cursou a graduação em Filosofia, Rago é professora titular colaboradora do Departamento de História do IFCH da Universidade Estadual de Campinas, tendo sido professora-visitante do Connecticut College e da Columbia University, nos Estados Unidos. Publicou livros que trouxeram uma importante contribuição para inúmeros campos de estudos, dentre os quais podemos citar Do Cabaré ao Lar. A utopia da sociedade disciplinar (1985, 2014); Os Prazeres da Noite. Prostituição e códigos da sexualidade feminina em São Paulo, 1890-1930 (1991, 2008); Entre a História e a Liberdade: Luce Fabbri e o anarquismo contemporâneo (2001); e A aventura de contarse: feminismos, escrita de si e invenções da subjetividade (2013).

Quem conhece o pensamento e a trajetória da historiadora sabe que seu trabalho é incansavelmente criativo, e essa é uma característica que fica evidente quando percorremos As Marcas da Pantera: percursos de uma historiadora (2021). Conversando com filósofos da diferença e com teóricas feministas, a autora nos oferece leituras e instrumentos teóricometodológicos para pensarmos a historicidade de nossas práticas e discursos. Também tece análises críticas contundentes sobre as imagens historicamente criadas sobre os corpos femininos, expondo suas violentas implicações. Além disso, o livro ainda é uma oportunidade para conhecermos mulheres que questionaram a lógica masculina, reinventaram as narrativas sobre o feminino e criaram outros modos de enxergar e de experienciar o mundo.

Ao iniciarmos a obra, encontramos textos que discutem a utilidade do pensamento de Michel Foucault para pensar a História. Como lembra Rago em "O efeito Foucault na historiografia brasileira" (1995), o filósofo transformou radicalmente a produção do conhecimento histórico, e não é por acaso que Paul Veyne tenha afirmado que "Foucault revolucionou a História". Foucault historicizou o que antes era tomado como a-histórico, como, por exemplo, a loucura, as prisões, o corpo, a sexualidade, os 
sentimentos. Também questionou a possibilidade de chegarmos à verdade objetiva, à essência, à totalidade dos objetos de que falamos, mostrando como somos efeitos de práticas discursivas que instituem a realidade. Trouxe ainda a percepção de que a História serve não para descobrirmos o que aconteceu, mas para entendermos como nos tornamos o que somos e como podemos ser diferentes.

$\mathrm{Na}$ análise foucaultiana, o/a intelectual é aquele/a que deve fazer o diagnóstico do presente, que deve desnaturalizá-lo, demonstrando que, por detrás daquilo que enxergamos como inevitável, há sempre racionalidades cambiantes, históricas, instáveis. O filósofo trouxe, então, uma perspectiva de História que, como Rago discute em seu texto "Epistemologia feminista, gênero e História" (1998), teve uma potência enorme na crítica feminista na medida em que contestava a noção de destino e mostrava que mudanças sempre são possíveis. Vale lembrar que vários dos operadores conceituais elaborados por Foucault tornaram-se importantes ferramentas analíticas para os feminismos, como "biopoder" e "dispositivo da sexualidade", que marcam como práticas históricas contingentes moldaram nossas noções sobre o sexo, desfazendo a possibilidade de haver categorias estanques, biológicas, naturais e, logo, eternas.

Foucault é o grande interlocutor de Rago, e a leitura dos textos da autora nos faz perceber que não foi à toa sua paixão pelo filósofo. Afinal, apaixonar-se pelo outro é sempre apaixonar-se por uma nova possibilidade de si mesmo. Embora críticos apressados tenham afirmado que o filósofo só se preocupou com o poder, Foucault foi alguém que apontou a necessidade de construirmos modos de existência libertários, indicou como nossas relações com nós mesmos ocupam um lugar fundamental nas lutas pela transformação do mundo, chamou a atenção para as práticas de cuidado de si inscritas na vida antiga, desafiou as tecnologias de poder e os pensamentos centristas, trouxe inúmeras possibilidades de pensar as práticas de liberdade e jamais concebeu o sujeito como uma estrutura definitiva e pronta. Aliás, tomou a vida como uma obra de arte a ser inventada, elaborada, lapidada, colorida. A possibilidade de si mesmo que o filósofo francês anunciava era uma possibilidade libertária, e é justamente esse compromisso com a liberdade que encontramos tão fortemente na obra de Rago.

Não há como mergulhar nos inúmeros textos da autora sem perceber sua paixão pela liberdade, pela transformação, pela reinvenção de si. Um sinal disso é o fato de ela nunca ter assumido que a dominação foi a única coisa que aconteceu com as mulheres. É certo que um dos seus enfoques 
foi investigar como os corpos femininos foram territórios da atribuição de sentidos misóginos, classicistas e racistas. É o que discute o artigo "Foucault, a histeria e a Aranha" (2013), no qual a teórica analisa como os discursos construídos sobre as mulheres nos marcos da teoria da degenerescência e do evolucionismo construíram imagens da feminilidade extremamente danosas para a nossa subjetividade. Já no texto "A autobiografia ficcional da Vênus Hotentote" (2010), a historiadora problematiza o regime de verdades colonial que transformou as mulheres negras em expressões da degeneração, da inferioridade, da sensualidade e da irracionalidade. É construído nesse ínterim um corpo exótico, espetáculo da diferença a ser contemplado por todos, como fica explícito na história de Sarah Baartman, uma das tantas mulheres do sul-global que foram vendidas e expostas como atrações públicas em espetáculos circenses europeus do século XIX.

Ao mesmo tempo em que expôs como nosso mundo foi definido e caracterizado por um referencial fálico fundamentado em oposições dicotômicas e hierárquicas, a autora também buscou olhar para as experiências históricas que tanto resistiram a essa racionalidade quanto inventaram outros modos de existência. Por isso seu enfoque às lutas anarquistas e às ativistas que marcaram o século XX. É o caso de Maria Lacerda de Moura (18871945), anarcofeminista mineira que questionou radicalmente os ideais da modernidade burguesa, a ideia da inferioridade feminina natural, a ideologia da domesticidade e o casamento monogâmico indissolúvel; e que, além disso, defendeu o direito ao prazer sexual e o amor livre, no auge da teoria de degenerescência, como conhecemos em "Um grito de liberdade: posfácio a Amai... E não vos multipliqueis, de Maria Lacerda de Moura" (2020), escrito por Margareth Rago e Patrícia Lessa. Também é o caso de Luce Fabbri (1908-2000), anarquista ítalo-uruguaia que, do mesmo modo, travou uma verdadeira luta para transformar o imaginário social e cultural, e com quem Rago teve a oportunidade de conviver, como conta em "A audácia de sonhar: memória e subjetividade em Luce Fabbri” (2002).

Outras personagens que ocuparam um lugar especial na obra da historiadora foram as artistas feministas, que igualmente abriram caminhos libertários ao transformarem a arte em arma político-cultural de crítica e de resistência. Dentre as artistas enfocadas pela autora está Carol Rama (19182015), artista italiana que pintou imagens de corpos não normativos, eróticos, obscenos, que se masturbam, transam, defecam; corpos com falos imensos que fazem orgias sexuais; corpos mutilados e amputados, ou em cadeiras de rodas e em camas de hospital. Enfim, espécies de "anticorpos" que parecem 
rir de um imaginário cristão que historicamente associou as mulheres ao pecado e à carne, fazendo da arte uma forma de investir contra as tecnologias do poder, como Rago discute em "Carol Rama, entre a sexualidade, a loucura e a dor" (2019). Também por meio dos escritos da historiadora conhecemos a obra de Kara Walker (1969-), artista norte-americana que faz da arte uma forma de denunciar a violência sexual, a hipersexualização e a exploração do trabalho das mulheres negras, desde as antigas plantações de açúcar.

Ainda encontramos no livro textos que analisam a relação entre o neoliberalismo e o feminismo no contexto brasileiro, e, mesmo nesse tema, a autora não deixa de enfatizar os espaços de liberdade criados historicamente frente a esse novo regime de verdades. Para pensar sobre isso, Rago também se inspira em Foucault, que procurou demonstrar como a racionalidade neoliberal, entendida como uma forma de conduzir as condutas, se estendeu para todas as dimensões da vida, produzindo uma subjetividade individualizante, formatando o mundo como se tudo fosse mercadoria, criando uma experiência de vida utilitária e fazendo com que nos sintamos "empresários de nós mesmos" - isto é, aqueles que precisam estar constantemente produzindo, competindo e aumentando seu capital humano. Paralelamente, o filósofo procurou demonstrar que sempre houve múltiplas formas de "contracondutas". Ou seja, múltiplas formas de se construir inventivamente, de se colocar no mundo, de se relacionar com os outros e consigo mesmo.

O conceito de "contracondutas" acabou se tornando uma importante ferramenta teórica para a leitura das formas de resistência às novas modalidades de controle neoliberais. Um dos pontos mais enfatizados por Rago é o de que, se as mulheres e os movimentos feministas se encontram ameaçados por esse novo regime de verdades neoliberal, os feminismos também operam uma série de contracondutas. Como a autora discute em textos como "Foucault, o neoliberalismo e as insurreições feministas" (2017), basta olharmos para os movimentos feministas que estouraram em nosso país no final dos anos 1960. Foi nesse momento que as mulheres criaram expressões estético-políticas em uma extensão nunca vista, começaram a se organizar cada vez mais em coletivos, colocaram a dimensão do erotismo em pauta, utilizaram o espaço do corpo e do prazer para reivindicar uma vida própria, saíram às ruas para denunciar assédios e feminicídios, dentre uma série de outras ações que desafiaram a cultura patriarcal. Para a historiadora, os feminismos estão no centro dos movimentos libertários, contribuindo para futuros mais dignos e justos. 
Como percebemos, os diferentes textos de Rago desmontam os discursos hegemônicos que nos constituíram e as perversas dicotomias das quais somos frutos. Também são textos que não apenas fazem um diagnóstico do presente, como buscam as diferentes tentativas empreendidas, sobretudo pelas mulheres, para transformar o mundo em um lugar mais libertário, filógino, antirracista, ético, bonito. Em um presente permeado pela apatia e pela incerteza, a autora nos presenteia com um livro que nos possibilita o reencantamento da vida, que nos nutre, que povoa nosso imaginário de referências e de conceitos, e que nos faz lembrar como somos inventores de nossas existências. Ler a obra da historiadora funciona como uma espécie de reabilitação para seguir operante na vida, que nos mostra que, se quisermos aterrissar em outros mundos, há uma bagagem. Há experiências concretas ao longo de nossa História, mostrando que, se a vida é um lugar do poder, ela é também um espaço da liberdade.

RECEBIDO EM: 20/04/2021

APROVADO EM: 16/05/2021 